\title{
Pliocene colonization of the Mediterranean by Great White Shark inferred from fossil records, historical jaws, phylogeographic and divergence time analyses
}

\author{
Agostino Leone $^{1}$ (D) | Gregory N. Puncher, ${ }^{2,3}$ | Francesco Ferretti ${ }^{4,5}$ | Emilio Sperone ${ }^{6}$ | \\ Sandro Tripepi $^{6}$ | Primo Micarelli ${ }^{7}$ | Andrea Gambarelli ${ }^{8}$ | Maurizio Sarà ${ }^{9}$ | \\ Marco Arculeo $^{9}$ | Giuliano Doria ${ }^{10}$ | Fulvio Garibaldi ${ }^{11}$ | Nicola Bressi ${ }^{12}$ | \\ Andrea Dall'Asta $^{12}$ | Daniela Minelli ${ }^{13}$ | Elisabetta Cilli ${ }^{14}$ | Stefano Vanni ${ }^{15}$ | \\ Fabrizio Serena $^{16}$ | Píndaro Díaz-Jaimes ${ }^{17}$ | Guy Baele ${ }^{18}$ | Alessia Cariani ${ }^{1}$ | Fausto Tinti ${ }^{1}$ \\ ${ }^{1}$ Department of Biological, Geological \& Environmental Sciences (BiGeA), Laboratory of Genetics \& Genomics of Marine Resources and Environment \\ (GenoDREAM), University of Bologna, Ravenna, Italy \\ ${ }^{2}$ Dept Biological Sciences, Canadian Rivers Institute, University of New Brunswick, Saint John, NB, Canada \\ ${ }^{3}$ Genomics Laboratory, Maurice-Lamontagne Institute, Fisheries and Oceans Canada, Mont-Joli, QC, Canada \\ ${ }^{4}$ Hopkins Marine Station, Department of Biology, Stanford University, Pacific Grove, CA, USA \\ ${ }^{5}$ Department of Fish and Wildlife Conservation, Virginia Tech, Blacksburg, VA, USA \\ ${ }^{6}$ DiBEST Department of Biology, Ecology and Earth Science, University of Calabria, Arcavacata di Rende, Italy \\ ${ }^{7}$ Sharks Studies Center (C.S.S.), Massa Marittima, Italy \\ ${ }^{8}$ Museum of Zoology and Comparative Anatomy of Modena, University of Modena and Reggio Emilia, Modena, Italy \\ ${ }^{9}$ Dipartmento di Scienze e Tecnologie Biologiche Chimiche e Farmaceutiche (STEBICEF), University of Palermo, Palermo, Italy \\ ${ }^{10}$ Civic Museum of Natural History "Giacomo Doria", Genova, Italy \\ ${ }^{11}$ Department of Earth Sciences, Environmental and Life, University of Genova, Genova, Italy \\ ${ }^{12}$ Civic Museum of Natural History of Trieste, Trieste, Italy \\ ${ }^{13}$ Museum of Comparative Anatomy, University of Bologna, Bologna, Italy \\ ${ }^{14}$ Department of Cultural Heritage, University of Bologna, Ravenna, Italy \\ ${ }^{15}$ Museum of Natural History of Firenze "La Specola", Firenze, Italy \\ ${ }^{16}$ Institute for Biological Resources and Marine Biotechnology (IRBIM), National Research Council - CNR, Mazara del Vallo (TP), Italy \\ ${ }^{17}$ Laboratorio de Genética de Organismos Acuáticos Instituto de Ciencias del Mar y Limnología, Universidad Nacional Autónoma de México, Mexico, D.F., Mexico \\ ${ }^{18}$ Department of Microbiology and Immunology, Rega Institute, KU Leuven, Leuven, Belgium
}

\section{Correspondence}

Agostino Leone, Department of Biological, Geological \& Environmental Sciences (BiGeA), Laboratory of Genetics \& Genomics of Marine Resources and Environment (GenoDREAM), University of Bologna, 48123 Ravenna, Italy.

Email: agostino.leone@unibo.it

Funding information

$\mathrm{AL}, \mathrm{GNP}, \mathrm{AC}$ and FT were funded by the University of Bologna by RFO 2016-2018 and Canziani grants to FT. AL is also funded by Italian Ministry for University and Research by a PhD grant 2015-2017. All the other authors were funded by respective

\section{Abstract}

Aim: Determine the evolutionary origin of the heretofore poorly characterized contemporary Great White Shark (GWS; Carcharodon carcharias) of the Mediterranean Sea, using phylogenetic and dispersal vicariance analyses to trace back its global palaeo-migration pattern.

Location: Mediterranean Sea.

Taxon: Carcharodon carcharias.

Methods: We have built the largest mitochondrial DNA control region (CR) sequence dataset for the Mediterranean GWS from referenced historical jaws spanning the 19 th and 20th centuries. Mediterranean and global GWS CR sequences were analysed 
institutions. GB acknowledges support from the Interne Fondsen KU Leuven/Internal Funds KU Leuven under grant agreement C14/18/094.

Handling Editor: Michelle Gaither for genetic diversity, phylogenetic relationships and divergence time. A Bayes factor approach was used to assess two scenarios of GWS lineage divergence and emergence of the Mediterranean GWS line using fossil records and palaeo-geographical events for calibration of the molecular clock.

Results: The results confirmed a closer evolutionary relationship between Mediterranean GWS and populations from Australia-New Zealand and the North-eastern Pacific coast rather than populations from South African and North-western Atlantic. The Mediterranean GWS lineage showed the lowest genetic diversity at the global level, indicating its recent evolutionary origin. An evaluation of various divergence scenarios determined the Mediterranean GWS lineage most likely appeared some 3.23 million years ago by way dispersal/vicariance from Australian/Pacific palaeo-populations.

Main conclusion: Based on the fossil records, phylogeographic patterns and divergence time, we revealed that the Mediterranean GWS population originated in the Pliocene following the Messinian Salinity Crisis. Colonization of the Mediterranean by GWS likely occurred via an eastward palaeo-migration of Australian/eastern Pacific elements through the Central American Seaway, before the complete closure of the Isthmus of Panama. This Pliocene origin scenario contrasts with a previously proposed scenario in which Australian GWS colonized the Mediterranean via antipodean northward migration resulting from navigational errors from South Africa during Quaternary climatic oscillations.

\section{KEYWORDS}

Carcharodon carcharias, divergence time, Great White Shark, historical DNA, Mediterranean, phylogeography

\section{1 | BACKGROUND}

Large predatory shark populations in the Mediterranean Sea have declined dramatically over the last century (Ferretti, Myers, Serena, \& Lotze, 2008). The loss of apex predators throughout the world's oceans over the past century is likely to have caused profound ecological alterations and potentially large-scale trophic cascades (Ferretti, Worm, Britten, Heithaus, \& Lotze, 2010; Myers, Baum, Shepherd, Powers, \& Peterson, 2007). Among the species that witnessed the most precipitous declines is the Great White Shark (Carcharodon carcharias, L. 1758, henceforth GWS; McPherson \& Myers, 2009), which is currently listed as Critically Endangered in European seas (Nieto et al., 2015). GWS are widespread throughout the globe, aside from the polar regions, with hotspots of abundance located off the coasts of South Africa, Australia, New Zealand, Japan, North and South America, and in the Mediterranean (Compagno, 1984; Fergusson, 1996). Integrated ecological, genetic and tagging data have revealed natal homing and philopatric behaviour of GWS, with extraordinary transoceanic migrations of both sexes between geographically distant populations in the Indian (Blower, Pandolfi, Bruce, Gomez-Cabrera, \& Ovenden, 2012; Bonfil et al., 2005; Pardini et al., 2001) and North Pacific Ocean (Domeier \& Nasby-Lucas,
2008; Jorgensen et al., 2010, 2012). In the Mediterranean, GWS have long been observed and documented by the public, resource users and scientists, who have provided opportunistic occurrence records, from direct sightings, commercial fisheries, records of bite marks found on prey and museum specimens dating back to the early 19th century (De Maddalena, 2006; Mancusi et al., 2002; Sperone et al., 2012). In the past, free-swimming individuals and pairs were frequently observed in areas where large pelagic fisheries were intense (e.g. the Sicilian Channel, the Ligurian and Tyrrhenian seas; Fergusson, 1996; Storai, Vanni, Zuffa, \& Biagi, 2005). A few records of GWS pups from Turkey and Tunisia, as well as juveniles in the Sicilian Channel, suggest that the Mediterranean may host GWS nursery areas (Fergusson, 1996; Kabasakal \& Gedikoğlu, 2008; Storai, Mojetta, Zuffa, \& Giulian, 2000). However, the natural history of Mediterranean GWS still remains largely uncharacterized.

Efforts have been made in the past to resolve the phylogenetic relationships of the Mediterranean GWS population using mitochondrial DNA (mtDNA) sequences (Gubili et al., 2010, 2015). Using up to five specimens from the Mediterranean, Gubili et al. (2010, 2015) concluded that the population is more closely related to populations in the Pacific Ocean (Australia, New Zealand and North-eastern Pacific) than to those from the western Indian Ocean (South Africa) and 
north-western Atlantic Ocean (Florida). Based on a nucleotide substitution rate between the two major lineages (North-eastern Pacific vs. North-West Atlantic and Eastern Indian) calibrated by the formation of the Isthmus of Panama (3.5 Ma) and the Sunda-Sahul Shelves (5 Ma), respectively, Gubili et al. (2010) suggested that Mediterranean GWS are descendants of a few disoriented individuals who immigrated from Australia/New Zealand during the Pleistocene (348-565 ka) by an antipodean route along the western coast of Africa. A scenario of multiple relatively recent colonization events was also considered, based on the haplotype relationships that were generated using a few historical and contemporary Mediterranean specimens (Gubili et al., 2015).

Collection of fresh GWS specimens in the Mediterranean has proven to be difficult in recent decades, due to their precipitous decline in abundance. However, there is a great number of referenced and dry-preserved GWS specimens in several Italian museums and private scientific archives, such as mounted skins, jaws, vertebrae and teeth collected from the Mediterranean during the last two centuries (De Maddalena, 2006; Mancusi et al., 2002). Recently developed ancient DNA (aDNA) techniques present a great opportunity for reconstructing the natural history of marine species using preserved historical materials (Hofreiter, Serre, Poinar, Kuch, \& Pääbo, 2001; Riccioni et al., 2010). Unfortunately, most historical GWS specimens have been archived in sub-optimal conditions, thereby compromising their potential for DNA-based applications. Moreover, many collectors are reluctant to loan specimens for molecular study, due to their intrinsic, sentimental and market value.

By analysing DNA extracted from preserved specimens of GWS caught during the last 195 years, from eight Italian museums and private collections, we have been able to explore the evolutionary history of the Mediterranean GWS. Using effective and affordable aDNA techniques widely used to extract and genotype DNA from historical specimens of marine fish, we have generated a publicly available mtDNA sequence dataset from 18 Mediterranean GWS individuals.

\section{2 | MATERIALS AND METHODS}

Full details of the collected historical GWS specimens, sampling procedures, protocols for aDNA extraction, PCR amplification of control region (CR), sequencing and sequence analyses are provided in the Supporting Information (Supplementary Methods in Appendix S1; Figures S1-S3 in Appendix S2; Tables S1-S3 in Appendix S3).

\subsection{Analysis of fossil evidence}

The extensive catalogue of taxon-specific GWS fossils featured in the online and open access Paleobiology Database (https://paleo biodb.org/\#/), and its associated R package 'paleobioDB' (Varela et al., 2015), was used to create a distribution and stratigraphic map of global GWS fossils. The downloaded database was filtered manually to avoid the use of homonym extinct taxa and dubious records.
Only reliable records specifically classified as $C$. carcharias and relative synonyms were retained (Table S4 in Appendix S3). A detailed search of the literature with a focus on $C$. carcharias fossils from the Mediterranean Sea was carried out to retain reliable fossil records and exclude potential misidentification of fossil specimens (Table S5 in Appendix S3; Adnet, Balbino, Antunes, \& Marín-Ferrer, 2009; Applegate \& Espinosa-Arrubarrena, 1996; Bianucci et al., 2002; Cigala-Fulgosi, 1990; Gottfried \& Fordyce, 2001; Marsili, 2006; Marsili, 2008). The fossil records from the paleobioDB database were checked for correctness using the references and fossil collections associated with the paleobioDB codes (Table S4 in Appendix S3). Records without descriptions of the fossil or without pictures, especially those from old references, as well as records with misidentified fossils (e.g. Isurus spp. or Carcharodon spp. identified as $C$. carcharias), were removed.

\section{2 | Time of the Most Recent Common Ancestor and estimation of evolutionary rate}

The divergence time analysis of the GWS lineages was carried out using Bayesian inference through Markov Chain Monte Carlo (MCMC) sampling as implemented in BEAST v1.10.0 (Suchard et al., 2018). An initial analysis using calibration priors without sequence data was carried out to determine if calibration priors interacted unexpectedly and to assess if the data were informative (Fulton \& Strobeck, 2010). A relaxed molecular clock and a constant population size coalescent model were used to recover time-stamped phylogenies in BEAST. To ensure convergence of the posterior distributions, three independent MCMC analyses were run (20 million steps, sampled every $1 \mathrm{k}$ generations, burn-in $50 \%)$. Convergence and effective sample sizes (ESS) were verified using Tracer v.1.7.0 (Rambaut, Drummond, Xie, Baele, \& Suchard, 2018). A Maximum Clade Credibility (MCC) tree was summarized using TREeAnNotator V.1.10.0 and visualized in FigTree v.1.4.3 (Rambaut, 2009). As the molecular clock is sensitive to bias when a short fragment with fewer polymorphisms is used, the Time of the Most Recent Common Ancestor (TMRCA) analyses were carried out using the two CR sequence datasets of different length (516 and $828 \mathrm{bp}$ ), as previously used in the haplotype network analysis (Supplementary Methods in Appendix S1). The divergence time of the GWS lineages was estimated using two alternative combinations of calibration priors in BEAST v1.10.0 (Suchard et al., 2018). The alternative combinations of calibration priors were built by integrating the estimated age of the earliest GWS fossil records (Applegate \& Espinosa-Arrubarrena, 1996) (Mean: 11.0 Ma; SD: 1.0) with two different secondary calibrations: (a) the best dated fossil record of GWS in the Mediterranean Sea, dated back to the Pliocene (Cigala-Fulgosi, 1990; Bianucci et al., 2002; Mean: 3.0 Ma; SD: $0.30 \mathrm{Ma}$ ), and (b) the molecular divergence previously estimated by Gubili et al. (2010; Mean: 0.4 Ma; SD: 0.15). Both combinations of calibration priors were implemented as normally distributed. Rather than using debated fossil records from the 
middle Miocene epoch (Gottfried \& Fordyce, 2001), we used the divergence time between the GWS and the outgroup Lamna nasus (GenBank acc. no. GU266755-GU266769) as an alternative first calibration. The divergence time of these two lineages has been estimated at around $46 \mathrm{Ma}$ (Martin, 1996) (Mean: $46.0 \mathrm{Ma}$; SD: 1.0).

\section{3 | Marginal likelihood estimation and testing divergence time hypotheses}

After setting the first calibration for the earliest fossil attributed to the GWS, the two alternative secondary calibrations could be compared by estimating log marginal likelihoods using generalized stepping-stone (GSS) sampling, as implemented in BEAUti v1.10.0 and BEAST v1.10.0 (Baele, Lemey, \& Suchard, 2015; Suchard et al., 2018). The log marginal likelihood values for the two different scenarios were first estimated using GSS sampling (100 stepping stones, 1 million iterations, logging every 1,000 iterations). A total of 101 power posteriors, with one million iterations each, were sampled using MCMC for the GSS approach. To select the alternative calibrations that fits best with the principal timing information fixed for both scenarios, the log Bayes factor was calculated for both scenarios using the formula $\log B F=\log \operatorname{Pr}(D \mid M 1)-\log \operatorname{Pr}(D \mid M 2)$, where $\log \operatorname{Pr}(D \mid M 1)$ is the log marginal likelihood for model 1 and logPr $(D \mid M 2)$ is the log marginal likelihood for model 2. This analysis was performed on both sequence datasets (i.e. 516 and 828 bp).

\section{4 | Reconstructing the historical biogeography}

Two approaches were implemented to reconstruct the historical biogeography of species: the statistical dispersal-vicariance analysis (S-DIVA; Yu, Harris, \& He, 2010), which is a parsimony method of historical biogeography, and dispersal-extinction-cladogenesis analysis (DEC; Ree \& Smith, 2008). An MCC estimated by using BEAST and TreeAnnotator on just haplotype sequences, and the specimen distribution through all biogeographical areas (A: Australia/New Zealand, AUS; B: North-eastern Pacific, NEP; C: Mediterranean, MED; D: South Africa, SA; E: North-western Atlantic, NWA) was used to perform the S-DIVA and DEC analyses implemented in RASP v. 4.0 (Yu, Harris, Blair, \& He, 2015).

\section{3 | RESULTS}

Partial CR sequences (515 bp) from 18 GWS historical specimens were obtained and deposited in GenBank (acc. no. MN718579-MN718596).

The multiple sequence alignment containing sequences from all 18 historical samples and four Mediterranean homologous modern sequences deposited in GenBank (HQ540294-HQ540296; JF715925; Table S3 in Appendix S3) showed an extremely

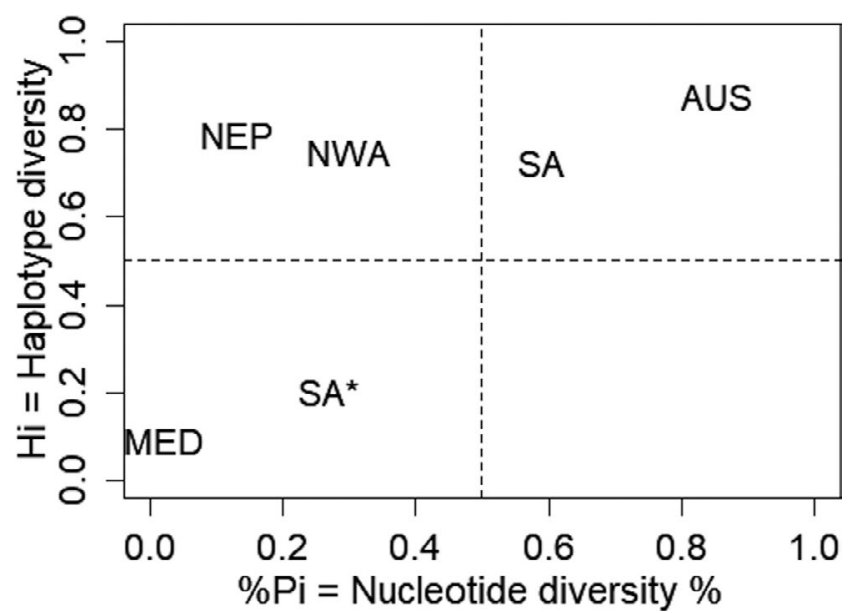

FIGURE 1 Plot of the haplotype and nucleotide diversity values (expressed as percentage values) of global populations of Carcharadon charcarias inferred using sequences from the mitochondrial control region AUS, Australia/New Zealand; MED, Mediterranean (516 bp; $n=22$ ); NEP, Northeastern Pacific; NWA, Northwestern Atlantic; SA, South-Africa. Asterisk indicates values reported by Andreotti et al. 2016 for the South African population

low nucleotide diversity among the $C R$ fragment $(<0.1 \%)$, with only one variable site at position 244 , in which the specimen FICC02LI (See Table S1 in Appendix S3), with GenBank acc. no. MN718587, showed a transition ( $>$ > G). A final alignment containing Mediterranean sequences merged with the homologous sequences from the other global populations $(N=99)$ resulted in a final dataset of $117 \mathrm{CR}$ sequences of $516 \mathrm{bp}$ in which an indel at position 60 was revealed.

The global ML haplotype network revealed 31 haplotypes (Figure S4 in Appendix S2) that were clustered in two main haplogroups differentiated by 28 mutations. As expected, based on the existing literature, the first haplogroup was formed by the individuals from the MED and the Pacific Ocean (AUS and NEP) and the second was composed of GWS from SA and the NWA. Three haplotypes of GWS collected in AUS (HQ414073, HQ414074 and AY026211; Table S3 in Appendix S3) clustered in the latter haplogroup and these individuals are SA-like individuals that likely migrated across the Indian Ocean (Blower et al., 2012; Pardini et al., 2001). The ML haplotype network built with 99 GWS sequences of 828 bp revealed 68 haplotypes and a similar topology (Figure S4 in Appendix S2) to the one reconstructed using the shorter sequence dataset, with two main haplogroups (AUS-NEP-MED vs. SA-NWA).

The cross-plot for the haplotype and nucleotide diversity of the Mediterranean and global populations revealed that the MED and AUS populations have the lowest and highest values for both indices respectively (Figure 1; Table S6 in Appendix S3). The NEP and NWA populations showed high haplotype diversity and low nucleotide diversity. The SA population exhibited quite opposite positions in the plot, depending on the reference study used (Pardini et al. (2001) and O'Leary et al. (2015) both offered high values for both indices and Andreotti et al. (2016) provided low values). 
No polymorphisms were detected among the four complete contemporary CR sequences isolated from Mediterranean GWS, demonstrating a low haplotype diversity among longer sequences as well, while the genetic diversity (e.g. nucleotide) is proportional to the length of the sequences.

\section{1 | Marginal likelihood estimation and test for divergence time hypotheses}

The application of the log Bayes factor formula gave significant support to the Pliocene calibration scenario in every model tested (Table 1). Based on the 828 bp dataset, the GWS Mediterranean population diverged from the Pacific populations approximately 3.23 $\mathrm{Ma}$, a time that is congruent with the estimated closure of the Central American Seaway, CAS (about 3.5 Ma), after the formation of the Isthmus of Panama (O'Dea et al., 2016). Considering the "Pleistocene divergence" scenario, we obtained a slight mismatch between the posterior distribution generated from the data and posterior distribution generated from specified calibration using priors only. This may suggest that a second Pleistocene calibration could be conflicting with the data and that a "Pliocene divergence" scenario is preferable.

\subsection{TMRCA and estimation of evolutionary rate}

The analysis of fossil evidence suggested that GWS experienced a long evolutionary history (Tables S4 and S5 in Appendix S3). The occurrence of GWS fossils in the Mediterranean area is high in the Pliocene, after the Messinian Salinity Crisis (MSC).

The $C R$ relaxed substitution rate range inferred from the TMRCA analysis was estimated at $0.38 \%-0.72 \%$ substitutions/site/Myr for the best model following the Bayes factor. Based on these estimates, the coalescence of the Mediterranean and Pacific GWS lineages was dated at 3.23 Ma for the alignment containing $828 \mathrm{bp}$ (Figure 2) and $1.81 \mathrm{Ma}$ for the alignment of $516 \mathrm{bp}$ (Figure S5 in Appendix S2).

\section{3 | Historical biogeography reconstruction}

The analysis of the ancestral ranges of GWS, using both S-DIVA and DEC approaches, suggested that the Mediterranean population is potentially the result of a dispersal-vicariance scenario. The biogeographical reconstruction of the Mediterranean lineage estimated using S-DIVA resulted in two principal ancestral ranges, AC (AUS-MED) and ABC (AUS-NEP-MED), with probabilities (relative frequencies) for each range of $52.44 \%$ and $46.69 \%$ respectively. Two minor ancestral ranges were detected with very low probability: $A B$ (AUS-NEP) and BC (NEP-MED), with probabilities of $0.52 \%$ and $0.35 \%$ respectively. The DEC analysis resulted in concordant results with two ancestral ranges, AC (AUS-MED); BC (NEP-MED), with probabilities of $50.01 \%$ and $49.99 \%$, respectively, supporting that the origin of the Mediterranean population is likely Australia and the North-Eastern Pacific. Both approaches suggest the following route of dispersal-vicariance: $A C>C A B>C \mid A B$. For both S-DIVA and DEC analyses, Australian and North-Eastern Pacific lineages originated from a Pacific ancestral range $A B$ (AUS-NEP) with a probability of $100 \%$.

\section{4 | DISCUSSION}

Our phylogenetic analysis of contemporary and historical sequences indicates that the existing population of GWS in the Mediterranean Sea could be a relic of the Pacific GWS clade. This scenario would suggest that Pacific-born ancestors migrated eastward across the ocean, before the closure of the CAS. Following this, these itinerant migrants would have colonized the North Atlantic Ocean before entering the Mediterranean Sea after the MSC. They would have entered the Mediterranean during a period of ecological upheaval, following the MSC which caused the extinction of the local marine megafauna due to the total or partial drying up of the nearly landlocked sea (GarciaCastellanos et al., 2009). This evolutionary pathway (Figure 3) is supported by Bayesian analyses of genetic diversity and divergence time estimates and it is coherent with the age of the main palaeogeographical events, palaeo-climatic patterns and fossil records. This pathway represents an alternative to the antipodean dispersal hypothesis (Gubili et al., 2010) which suggested that a few Australian/ New Zealand founder females that visited the Good Hope Cape area became confused by Pleistocene climatic oscillations, swam northward and found themselves in the Mediterranean Sea.

Our phylogenetic analysis of the CR sequences as well as the plot analysis of haplotype confirmed that the Mediterranean GWS have a closer evolutionary relationship with the Australian/New Zealand and North-eastern Pacific lineages than with the South African and North-western Atlantic lineage. These results are in agreement with previous studies (Andreotti et al., 2016; Blower et al., 2012; Gubili et al., 2010). The Mediterranean GWS exhibited a very shallow mtDNA genetic variation with only two haplotypes and extremely low genetic diversity. Among the modern samples collected from throughout the world that have been analysed to date, the Mediterranean GWS have provided the lowest estimates of genetic diversity. This is likely an indication that the population is relatively young and has likely originated by a founder event by a limited number of mtDNA lineages or that the population has experienced a recent population bottleneck (Group 1 of Grant \& Bowen, 1998; Grant \& Waples, 2000). Within the Pacific/ Mediterranean mitochondrial clade, the Australian/New Zealand GWS population was identified as the most ancestral with a long evolutionary/demographic history and divergent haplotypes that have accumulated over long periods of time (as indicated by the high haplotype and nucleotide diversity values; Group 3 of Grant \& Bowen, 1998; Grant \& Waples, 2000). An intermediate evolutionary position in the clade could be that of the North-eastern Pacific GWS population which possesses high haplotype diversity 
TAB LE 1 Best model selection based on Bayes factors of tree topologies reconstructed with the earliest fossil occurrences using 828 and 516 bp mitochondrial control region sequences

\begin{tabular}{|c|c|c|c|c|c|}
\hline Model & Dataset & Node1 & Node2 & logML_GSS & logBF_GSS \\
\hline \multirow[t]{2}{*}{ MED Pliocene divergence } & 828 bp & Ingroup & MED/Pacific & & \\
\hline & & $\begin{array}{l}\text { Mean: } 11 \mathrm{Ma}, \mathrm{SD}: \\
1.0 \mathrm{Ma}\end{array}$ & $\begin{array}{l}\text { Mean: 3.0 Ma, SD: } \\
0.30 \mathrm{Ma}\end{array}$ & -2455.2796 & 0 (Best) \\
\hline \multirow{2}{*}{$\begin{array}{l}\text { MED Pleistocene } \\
\text { divergence }\end{array}$} & 828 bp & Ingroup; & MED/Pacific & & \\
\hline & & $\begin{array}{l}\text { Mean: } 11 \mathrm{Ma}, \mathrm{SD}: \\
1.0 \mathrm{Ma}\end{array}$ & Mean: 0.4Ma, SD: 0.15 Ma & -2458.1264 & 2.8468 \\
\hline \multirow[t]{2}{*}{ MED Pliocene divergence } & 516 bp & Ingroup; & MED/Pacific & & \\
\hline & & $\begin{array}{l}\text { Offset: } 11 \mathrm{Ma}, \mathrm{SD} \text { : } \\
1.0 \mathrm{Ma}\end{array}$ & $\begin{array}{l}\text { Mean: } 3.0 \mathrm{Ma}, \mathrm{SD}: \\
0.30 \mathrm{Ma}\end{array}$ & -1440.6171 & 0 (Best) \\
\hline \multirow{2}{*}{$\begin{array}{l}\text { MED Pleistocene } \\
\text { divergence }\end{array}$} & $516 \mathrm{bp}$ & Ingroup; & MED/Pacific & & \\
\hline & & $\begin{array}{l}\text { Offset: } 11 \mathrm{Ma}, \mathrm{SD} \text { : } \\
1.0 \mathrm{Ma}\end{array}$ & Mean: 0.4 Ma, SD: 0.15 Ma & -1443.0069 & 2.3898 \\
\hline
\end{tabular}

Note: Node constraints and calibration parameters on the phylogeographical tree of Carcharodon carcharias for the two divergence models are also provided. logML_GSS: log marginal likelihood from generalized stepping stone model, BF_GSS: Bayes factors calculated using the logML_GSS. Models are ranked according to the logML values.

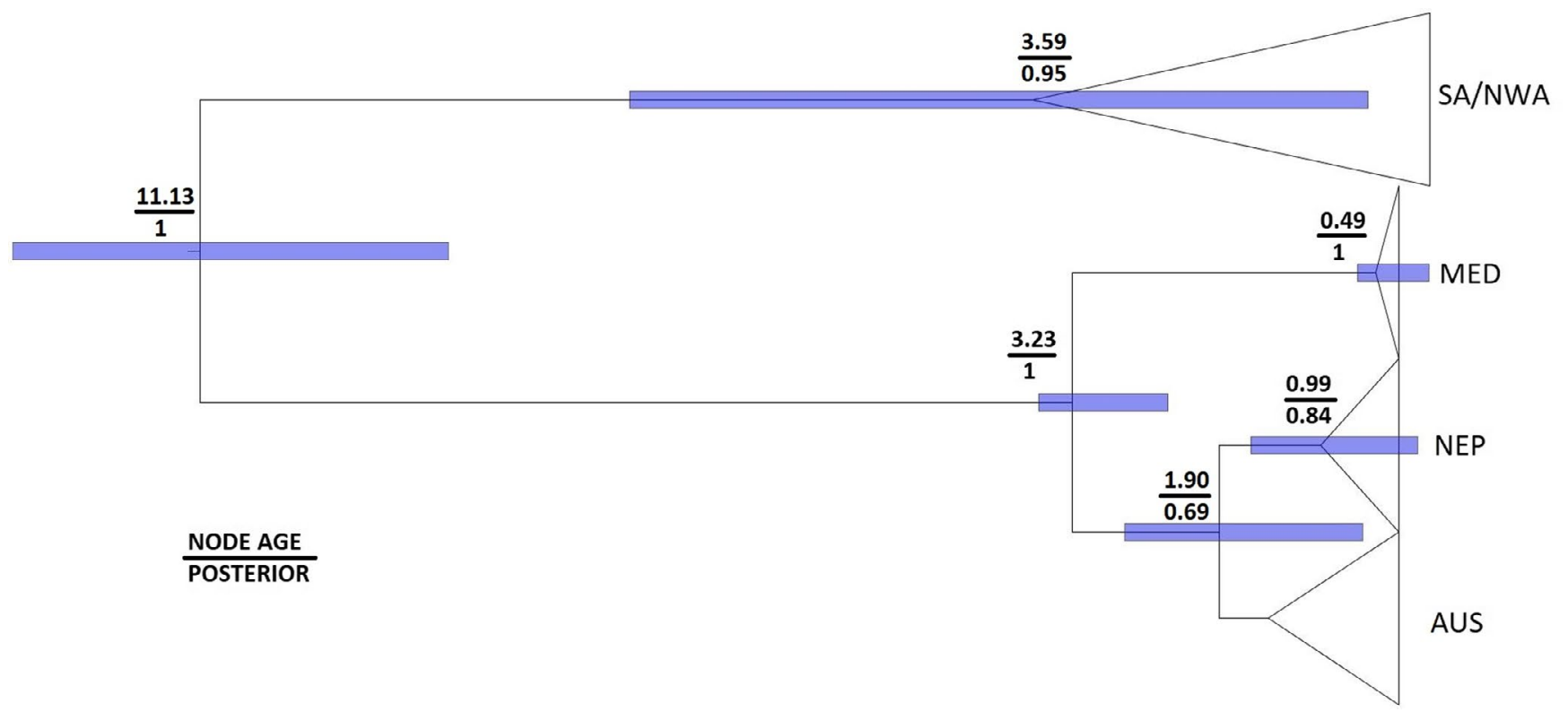

FIGURE 2 Bayesian divergence time tree of populations of Carcharadon charcarias inferred using sequences from the mitochondrial control region (828 bp). High posterior density (95\%) values are featured as blue bars. Nodes with posterior values $<0.5$ are not shown. Abbreviations are provided in Figure 1

and low nucleotide diversity. This pattern is indicative of a population that has experienced a bottleneck event followed by rapid demographic growth and accumulation of mutations (Group 2 of Grant \& Bowen, 1998; Grant \& Waples, 2000). Both S-DIVA and DEC analyses suggest that the Mediterranean GWS originated from a dispersal-vicariance event via eastward dispersal from a few Australian/Pacific individuals during the Pliocene. The founder event that gave origin to the modern Mediterranean GWS was dated by the TMRCA analysis, with high statistical support, to 3.23 Ma, during the Piacenzian Age (3.6-2.58 Ma). This is much earlier than the estimate provided by the antipodean dispersal hypothesis (348-565 ka; Calabrian, Pleistocene), which is based on a mtDNA substitution rate of $1.19 \%-0.74 \%$ of divergence between lineages per million year (Gubili et al., 2010). These rates of evolutionary change were calibrated by Gubili et al. (2010) using estimates of vicariance events that separated GWS populations from the North-eastern Pacific and North-western Atlantic oceans (i.e. the rising of the Isthmus of Panama dated at 3.5 Ma; O'Dea et al., 2016) and the Western Pacific and Indian oceans (i.e. the rising of the Sunda-Sahul shelves dated at $5 \mathrm{Ma}$; Haq, Hardenbol, 


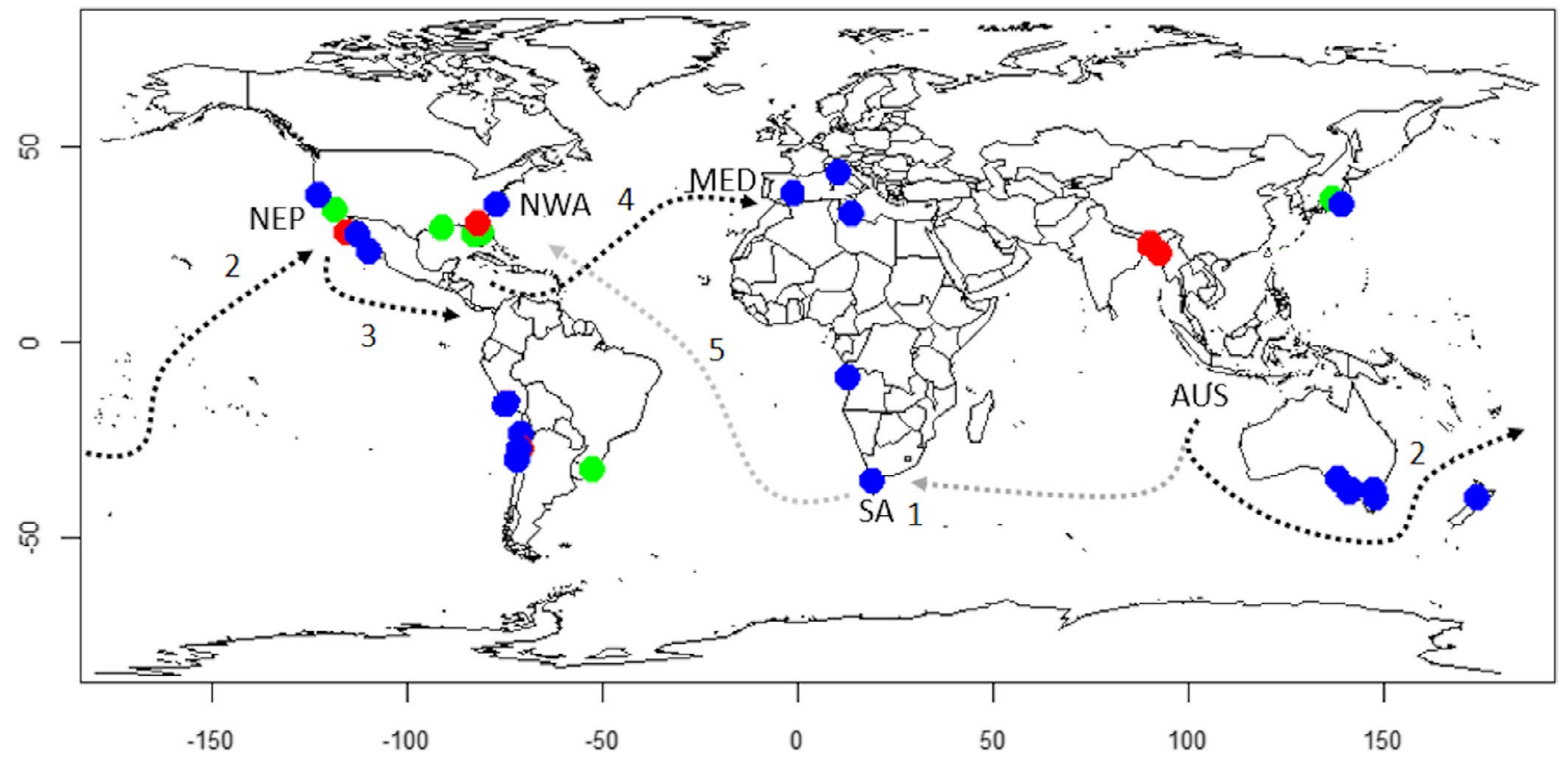

FIGURE 3 Global dispersal and Pacific/Mediterranean vicariance hypothesis for Carcharadon charcarias. Ancient great white sharks from the Pacific Ocean, namely Australia, dispersed via two routes: westward to South African coasts (1, light grey dotted line) and eastward to the Northeastern Pacific Ocean (2, black dotted line). The Pacific Great White Sharks were free to move eastward to the Atlantic, and in the Pliocene to an ancient Mediterranean Sea after the Messinian Salinity Crisis (3-4). Past climatic oscillation due to the closure of the Central America Seaway and the formation of the Isthmus of Panama, could have caused a local extinction or an eastward mass migration of white shark from the North Atlantic Ocean, isolating the Mediterranean population from other ancestral populations. The North Atlantic was colonized, then, in relatively recent history, when the climate conditions became more suitable (5). Fossil records extrapolated from the Paleobiology Database are indicated with colored points (red: Miocene, blue: Pliocene, green: Pleistocene). The map was created using 'paleobioDB' package in R version 3.5.1 (Varela et al., 2015). Abbreviations are provided in Figure 1

\& Vail, 1987). However, all phylogenetic analyses carried out so far (Andreotti et al., 2016; Gubili et al., 2010; present work) have revealed that the North-western Atlantic GWS are phylogenetically linked to the South African population but not to the Northeastern Pacific GWS. Therefore, the use of the vicariance event separating Atlantic and Pacific GWS might have led to an overestimation of the mutation rate and the subsequent time of divergence between Mediterranean and Pacific GWS at 348-565 ka during the Pleistocene.

The origination time of the species is still debated (see dedicated paragraph in Gottfried \& Fordyce, 2001). Despite the fossil records from the Miocene are less common, this should not exclude a Miocene origin of the species. Moreover, the molecular clock analysis suggested a divergence between Carcharodon and Isurus dated back to $43 \mathrm{Ma}$ (Martin, 1996), in contrast with a Pliocene origin of the C. carcharias from I. hastalis. However, a more dedicated study on the fossil history is needed to better clarify the origination time of the species.

Abundant fossil data suggest that GWS have inhabited the Mediterranean Sea since the early Pliocene, following the MSC, with numerous specimens estimated to be between $\sim 5$ and $\sim 2 \mathrm{Ma}$ old, with peaks of abundance occurring during the Pliocene (Adnet et al., 2009; Bianucci et al., 2002; Cigala-Fulgosi, 1990; Marsili, 2008). After these palaeoclimatic phases, GWS could have colonized the Mediterranean Sea occupying the ecological niches left empty by other apex marine predators, such as the giant megatooth shark Carcharocles megalodon, which went extinct between 3.5 and 2.6 Ma (Pimiento \& Clements, 2014). Fossil evidence from Central America suggests that many species of sharks and marine mammals that were part of the region's faunal assemblage may have migrated across the CAS continuously before the formation of the Isthmus of Panama (Pimiento et al., 2013; Steeman et al., 2009; Velez-Juarbe, Wood, De Gracia, \& Hendy, 2015). Upon the closure of the CAS, the newly formed Gulf Stream current could have facilitated a trans-Atlantic migration by way of the easterly current and subsequent eastward dispersion of nutrients and, consequently, food resources. There is evidence that intense fluctuations in the speed of the Gulf Stream occurred during the formation of the Isthmus of Panama, reaching a height during the late Miocene and early Pliocene ( 6.1-4.8 Ma; Kaneps, 1979). The intensification of currents coincides with the end of the MSC (5.33 Ma), which culminated with the Zanclean inflow in the Mediterranean Sea (Garcia-Castellanos et al., 2009). All of these oceanographic phenomena are concordant with our estimated divergence of the Mediterranean GWS population.

A potential earlier formation of the Isthmus of Panama (Bacon et al., 2015; Lessios, 2015; Montes et al., 2015; O'Dea et al., 2016) would not affect our results, as it is plausible that the Pacific lineage 
that gave rise to the MED population may already have been present in the North Atlantic before the closure of the CAS. Moreover, some researchers have suggested that the Caribbean Sea and Pacific Ocean may have remained intermittently connected by shallow waters other than the CAS (Jaramillo et al., 2017). The global phylogeography of contemporary GWS populations reveals a discontinuous distribution of the Pacific/Mediterranean GWS evolutionary lineage in the North Atlantic being interrupted by the recent colonization of the North-western Atlantic area by the Indian lineage. The phylogenetic analyses highlighted that the GWS of North-western Atlantic population does not exhibit a separated mtDNA cluster like the Pacific and Mediterranean populations, and it form a unique lineage with the South Africa (Figure S4 in Appendix S2). This evidence is suggestive of a recent evolutionary history or a population bottleneck followed by population growth and accumulation of mutations.

A local extinction of the past Pacific GWS lineage in the North Atlantic Ocean and further replacement by components of the Indian lineage could explain such a phylogeographic discontinuity. An extensive analysis of the fossil records highlighted an exceptional extinction rate of the marine fauna, including sharks, during the Pliocene epoch (Pimiento et al., 2017). Furthermore, the highest extinction rates occurred in the late Pliocene, between 3.8 and 2.4 $\mathrm{Ma}$, which coincides with the Mediterranean population divergence time, and may have led to the local extinction of the ancient Atlantic population of GWS.

Additional genetic and tagging studies are required to determine if the Mediterranean GWS are ecologically and reproductively isolated from the adjacent populations occupying the North Atlantic Ocean. This issue is of high priority for the development of efficient conservation actions and implementation of management strategies. Despite this knowledge gap, some information can be gleaned from the other populations in the Atlantic, as well as other species. For example, several other epipelagic sharks migrate throughout the temperate waters of the Atlantic and several are suspected of having nursery areas in the mid-Atlantic Ridge (Kohler, Turner, Hoey, Natanson, \& Briggs, 2002; O'Leary et al., 2015; Stevens, 2010; Vandeperre et al., 2014). Elsewhere, in the Indian Ocean, GWS have been observed migrating between Australia and South Africa, whereas in the Pacific, GWS frequently migrate between the western coast of North America and Hawaii (Blower et al., 2012; Bonfil et al., 2005; Jorgensen et al., 2010, 2012). Clearly, the species is not averse to far reaching longitudinal movements. However, antipodean connections appear less frequently and evidence for them is limited to variations in the genetic code (O'Leary et al., 2015). The latitudinal distribution of GWS could be limited by thermal tolerance, prey availability, social structure and fidelity to nursery areas (Cliff, Dudley, \& Davis, 1989; Curtis et al., 2014).

Our results suggest that the Mediterranean GWS have a more ancient origin than previously thought, and that this population is genetically disconnected from the adjacent Atlantic population. Due to historical and widespread declines in sharks in the Mediterranean Sea (Colloca et al., 2013; Ferretti et al., 2008; Ferretti, Osio, Jenkins, Rosenberg, \& Lotze, 2013) as well as the ongoing over-exploitation of marine resources in the region, the current white shark population is critically endangered (Dulvy, Allen, Ralph, \& Walls, 2016). This distinct genetic pool represents a valuable, albeit extremely vulnerable, component of the genetic diversity of a species that is endangered worldwide. Losing the Mediterranean GWS population would thus represent a significant blow to the global conservation of this species. Continued characterization of this population's ecology, spatial dynamics and population structure is paramount for effective management and restoration of this important top predator's ecological role in the region.

\section{ACKNOWLEDGEMENTS}

We are indebted to Alessandro Velonà, Adriana Villamor and Marco Stagioni for providing valuable technical support and advice. Clemente Ventrone and Gerlando Spagnolo provided samples from Favignana tuna trap.

\section{DATA AVAILABILITY STATEMENT}

The sequence data obtained in this study have been deposited to the GenBank database of the National Center for Biotechnology Information under accession numbers MN718579-MN718596.

\section{ORCID}

Agostino Leone (iD https://orcid.org/0000-0002-3927-7563

\section{REFERENCES}

Adnet, S., Balbino, A. C., Antunes, M. T., \& Marín-Ferrer, J. M. (2009). New fossil teeth of the white shark (Carcharodon carcharias) from the early Pliocene of Spain. Implication for its paleoecology in the Mediterranean. Neues Jahrbuch Für Geologie Und Paläontologie - Abhandlungen, 256(1), 7-16. https://doi.org/10.1127/0077-7749/2009/0029

Andreotti, S., von der Heyden, S., Henriques, R., Rutzen, M., Meÿer, M., Oosthuizen, H., \& Matthee, C. A. (2016). New insights into the evolutionary history of white sharks, Carcharodon carcharias. Journal of Biogeography, 43(2), 328-339. https://doi.org/10.1111/ jbi.12641

Applegate, S. P., \& Espinosa-Arrubarrena, L. (1996). Thefossil historyofCarcharodonand its possible ancestor, Cretolamna: A study in tooth identification. In A. P. Klimley \& D. G. Ainley (Eds.), Great white sharks: The biology of Carcharodon carcharias (pp. 19-36). San Diego, CA: Academic Press.

Bacon, C. D., Silvestro, D., Jaramillo, C., Smith, B. T., Chakrabarty, P., \& Antonelli, A. (2015). Biological evidence supports an early and complex emergence of the Isthmus of Panama. Proceedings of the National Academy of Sciences of the United States of America, 112(19), 61106115. https://doi.org/10.1073/pnas.1423853112

Baele, G., Lemey, P., \& Suchard, M. A. (2015). Genealogical working distributions for Bayesian model testing with phylogenetic uncertainty. Systematic Biology, 65(2), 250-264. https://doi.org/10.1093/sysbio/ syv083

Bianucci, G., Bisconti, M., Landini, W., Storai, T., Zuffa, M., Giuliani, S., \& Mojetta, A. (2002). Trophic interaction between white shark, Carcharodon carcharias, and cetaceans: A comparison between Pliocene and recent data from Central Mediterranean Sea. In M. Vacchi, G. Lamesa, F. Serena, \& B. Seret (Eds.), Proceedings of the 4th European Elasmobranch Association Meeting 28-30 November 2000 (pp. 33-48). Livorno, Italy: ICRAM, ARPAT \& SFI.

Blower, D. C., Pandolfi, J. M., Bruce, B. D., Gomez-Cabrera, M. D., \& Ovenden, J. R. (2012). Population genetics of Australian white sharks 
reveals fine-scale spatial structure, transoceanic dispersal events and low effective population sizes. Marine Ecology Progress Series, 455, 229-244. https://doi.org/10.3354/meps09659

Bonfil, R., Meÿer, M., Scholl, M. C., Johnson, R., O'Brien, S., Oosthuizen, H., ... Paterson, M. (2005). Transoceanic migration, spatial dynamics, and population linkages of white sharks. Science, 310(5745), 100103. https://doi.org/10.1126/science.1114898

Cigala-Fulgosi, F. (1990). Predation (or possible scavenging) by a great white shark on an extinct species of bottlenosed dolphin in the Italian Pliocene. Tertiary Research, 12, 17-36.

Cliff, G., Dudley, S. F. J., \& Davis, B. (1989). Sharks caught in the protective gill nets off Natal, South Africa. 2. The great white shark Carcharodon carcharias (Linnaeus). South African Journal of Marine Science, 8, 131-144. https://doi.org/10.2989/0257761890 9504556

Colloca, F., Cardinale, M., Maynou, F., Giannoulaki, M., Scarcella, G., Jenko, K., ... Fiorentino, F. (2013). Rebuilding Mediterranean fisheries: A new paradigm for ecological sustainability. Fish and Fisheries, 14(1), 89-109. https://doi.org/10.1111/j.1467-2979.2011.00453.x

Compagno, L. J. V. (1984). FAO Species Catalogue. Vol. 4. In W. Fischer \& C. E. Nauen (Eds.), Sharks of the world. An annotated and illustrated catalogue of shark species known to date. Part 1 - Hexanchiformes to Lamniformes. FAO Fisheries Synopsis, (vol. 125(4/1), pp. 1-249). Rome: Fishery Resources and Environment Division, Food and Agriculture Organization of the United Nations (FAO).

Curtis, T. H., McCandless, C. T., Carlson, J. K., Skomal, G. B., Kohler, N. E., Natanson, L. J., ... Pratt, H. L. (2014). Seasonal distribution and historic trends in abundance of white sharks, Carcharodon carcharias, in the Western North Atlantic Ocean. PLoS ONE, 9(6), e99240. https ://doi.org/10.1371/journal.pone.0099240

De Maddalena, A. (2006). A catalogue of great white sharks Carcharodon carcharias (Linnaeus, 1758) preserved in European museums. Journal of the National Museum, Natural History Series, 175(3-4), 109-125.

Domeier, M. L., \& Nasby-Lucas, N. (2008). Migration patterns of white sharks Carcharodon carcharias tagged at Guadalupe Island, Mexico, and identification of an eastern Pacific shared offshore foraging area. Marine Ecology Progress Series, 370, 221-237. https://doi. org/10.3354/meps07628

Dulvy, N. K., Allen, D. J., Ralph, G. M., \& Walls, R. H. L. (2016). The conservation status of sharks, rays and Chimaeras in the Mediterranean Sea. Malaga, Spain: IUCN.

Fergusson, I. K. (1996). Distribution and autoecology of the white shark in the Eastern North Atlantic and the Mediterranean Sea. In A. P. Klimley \& D. G. Ainley (Eds.), Great white sharks: The biology of Carcharodon carcharias (pp. 321-345). San Diego, CA: Academic Press.

Ferretti, F., Myers, R. A., Serena, F., \& Lotze, H. K. (2008). Loss of large predatory sharks from the Mediterranean Sea. Conservation Biology, 22(4), 952-964. https://doi:10.1111/j.1523 1739.2008.00938.x.

Ferretti, F., Osio, G. C., Jenkins, C. J., Rosenberg, A. A., \& Lotze, H. K. (2013). Long-term change in a meso-predator community in response to prolonged and heterogeneous human impact. Scientific Reports, 3, 1057. https://doi.org/10.1038/srep01057

Ferretti, F., Worm, B., Britten, G. L., Heithaus, M. R., \& Lotze, H. K. (2010). Patterns and ecosystem consequences of shark declines in the ocean. Ecology Letters, 13(8), 1055-1071. https://doi. org/10.1111/j.1461-0248.2010.01489.x

Fulton, T. L., \& Strobeck, C. (2010). Multiple fossil calibrations, nuclear loci and mitochondrial genomes provide new insight into biogeography and divergence timing for true seals (Phocidae, Pinnipedia). Journal of Biogeography, 37(5), 814-829. https://doi. org/10.1111/j.1365-2699.2010.02271.x

Garcia-Castellanos, D., Estrada, F., Jiménez-Munt, I., Gorini, C., Fernandéz, M., Vergés, J., \& De Vicente, R. (2009). Catastrophic flood of the Mediterranean after the Messinian salinity crisis. Nature, 462, 778-781. https://doi.org/10.1038/nature08555

Gottfried, M. D., \& Fordyce, R. E. (2001). An associated specimen of Carcharodon angustidens (Chondrichthyes, Lamnidae) from the late Oligocene of New Zealand, with comments on Carcharodon interrelationships. Journal of Vertebrate Paleontology, 21(4), 730739. https://doi.org/10.1671/0272-4634(2001)021[0730:AASOC A]2.0.CO;2

Grant, W. S., \& Bowen, B. W. (1998). Shallow population histories in deep evolutionary lineages of marine fishes: Insights from sardines and anchovies and lessons for conservation. Journal of Heredity, 89(5), 415-426. https://doi.org/10.1093/jhered/89.5.415

Grant, W. S., \& Waples, R. S. (2000). Spatial and temporal scales of genetic variability in marine and anadromous species: Implications for fisheries oceanography. In P. J. Harrison \& T. R. Parsons (Eds.), Fisheries oceanography: An integrative approach to fisheries ecology and management (pp. 63-93). Oxford, UK: Blackwell Science.

Gubili, C., Bilgin, R., Kalkan, E., Karhan, S. Ü., Jones, C. S., Sims, D. W., ... Noble, L. R. (2010). Antipodean white sharks on a Mediterranean walkabout? Historical dispersal leads to genetic discontinuity and an endangered anomalous population. Proceedings of the Royal Society B: Biological Sciences, 278(1712), 1679-1686 https://doi.org/10.1098/ rspb.2010.1856

Gubili, G., Robinson, C. E. C., Cliff, G., Wintner, S. P., de Sabata, E., De Innocentiis, S., \& Jones, C. S. (2015). DNA from historical and trophy samples provides insights into white shark population origins and genetic diversity. Endangered Species Research, 27(3), 233-241. https:// doi.org/10.3354/esr00665

Haq, B. U., Hardenbol, J., \& Vail, P. R. (1987). Chronology of fluctuating sea levels since the Triassic. Science, 235(4793), 1156-1167. https:// doi.org/10.1126/science.235.4793.1156

Hofreiter, M., Serre, D., Poinar, N. H., Kuch, M., \& Pääbo, S. (2001). Ancient DNA. Nature Reviews Genetics, 2, 353-359. https://doi. $\operatorname{org} / 10.1038 / 35072071$

Jaramillo, C., Montes, C., Cardona, A., Silvestro, D., Antonelli, A., \& Bacon, C. (2017). Formation of the Isthmus of Panama" by O'Dea et al. Science Advances, 3(6), e1602321. https://doi.org/10.1126/ sciadv.1602321

Jorgensen, S. J., Arnoldi, N. S., Estess, E. E., Chapple, T. K., Rückert, M., Anderson, S. D., \& Block, B. A. (2012). Eating or meeting? Cluster analysis reveals intricacies of white shark (Carcharodon carcharias) migration and offshore behavior. PLoS ONE, 7, e47819. https://doi. org/10.1371/journal.pone.0047819

Jorgensen, S. J., Reeb, C. A., Chapple, T. K., Anderson, S., Perle, C., Van Sommeran, S. R., ... Block, B. A. (2010). Philopatry and migration of Pacific white sharks. Proceedings of the Royal Society B: Biological Sciences, 277(1682), 679-688. https://doi.org/10.1098/ rspb.2009.1155

Kabasakal, H., \& Gedikoğlu, Ö. S. (2008). Two new-born great white sharks, Carcharodon carcharias (Linnaeus, 1758) (Lamniformes; Lamnidae) from Turkish waters of the north Aegean Sea. Acta Adriatica, 49, 125-135.

Kaneps, A. G. (1979). Gulf stream: Velocity fluctuations during the late Cenozoic. Science, 204(4390), 297-301. https://doi.org/10.1126/ science.204.4390.297

Kohler, N. E., Turner, P. A., Hoey, J. J., Natanson, L. J., \& Briggs, R. (2002). Tag and recapture data for three pelagic shark species: Blue shark (Prionace glauca), shortfin mako (Isurus oxyrinchus), and porbeagle shark (Lamna nasus) in the North Atlantic Ocean. ICCAT Collective Volumes of Scientific Papers, 54, 1231-1260.

Lessios, H. A. (2015). Appearance of an early closure of the Isthmus of Panama is the product of biased inclusion of data in the metaanalysis. Proceedings of the National Academy of Sciences of the United States of America, 112(43), E5765-E5765. https://doi.org/10.1073/ pnas. 1514719112 
Mancusi, C., Nicolosi, P., Arculeo, M., Barbagli, F., Carlini, R., Costantini, M., \& Vacchi, M. (2002). The presence of elasmobranchs in the collections of the main Italian natural history museums. In M. Vacchi, G. Lamesa, F. Serena, \& B. Seret (Eds.), Proceedings of the 4th European Elasmobranch Association Meeting 28-30 November 2000 (pp. 97108). Livorno, Italy: ICRAM, ARPAT \& SFI.

Marsili, S. (2006). Analisi Sistematica, Paleoecologica e Paleobiogeografica della Selaciofauna plio-pleistocenica del Mediterraneo (Doctoral dissertation). University of Pisa, Pisa, Italy.

Marsili, S. (2008). Systematic, paleoecologic and paleobiogeographic analysis of the Plio-Pleistocene Mediterranean elasmobranch fauna. Atti della Società Toscana di Scienze Naturali, Memorie, Serie A, 113, 81-88.

Martin, A. P. (1996). Systematics of the Lamnidae and the origination time of Carcharodon carcharias inferred from the comparative analysis of mitochondrial DNA sequences. In A. P. Klimley \& D. G. Ainley (Eds.), Great white sharks: The biology of Carcharodon carcharias (pp. 49-53). San Diego, CA: Academic Press.

McPherson, J. M., \& Myers, R. A. (2009). How to infer population trends in sparse data: Examples with opportunistic sighting records for great white sharks. Diversity and Distributions, 15(5) , 880-890. https ://doi.org/10.1111/j.1472-4642.2009.00596.x

Montes, C., Cardona, A., Jaramillo, C., Pardo, A., Silva, J. C., Valencia, V., ... Nino, H. (2015). Middle Miocene closure of the Central American Seaway. Science, 348(6231), 226-229. https://doi.org/10.1126/scien ce.aaa2815

Myers, R. A., Baum, J. K., Shepherd, T. D., Powers, S. P., \& Peterson, C. H. (2007). Cascading effects of the loss of apex predatory sharks from a coastal ocean. Science, 315(5820), 1846-1850. https://doi. org/10.1126/science.1138657

Nieto, A., Ralph, G. M., Comeros-Raynal, M. T., Kemp, J., García Criado, M., Allen, D. J., ... Williams, J. T. (2015). European red list of marine fishes. Luxembourg, EU: Rosseels Printing.

O'Dea, A., Lessios, H. A., Coates, A. G., Eytan, R. I., Restrepo-Moreno, S. A., Cione, A. L., ... Jackson, J. B. C. (2016). Formation of the Isthmus of Panama. Science Advances, 2(8), e1600883. https://doi.org/10.1126/ sciadv.1600883

O'Leary, S. J., Feldheim, K. A., Fields, A. T., Natanson, L. J., Wintner, S., Hussey, N., ... Chapman, D. D. (2015). Genetic diversity of white sharks, Carcharodon carcharias, in the Northwest Atlantic and Southern Africa. Journal of Heredity, 106(3), 258-265. https://doi. org/10.1093/jhered/esv001

Pardini, A. T., Jones, C. S., Noble, L. R., Kreiser, B., Malcolm, H., Bruce, B. D., ... Martin, A. P. (2001). Sex-biased dispersal of great white sharks. Nature, 412(6843), 139-140. https://doi. org/10.1038/35084125

Pimiento, C., \& Clements, C. F. (2014). When did Carcharocles megalodon become extinct? A new analysis of the fossil record. PLoS ONE, 9(10), e111086. https://doi.org/10.1371/journal.pone.0111086

Pimiento, C., Gonzalez-Barba, G., Hendy, A. J. W., Jaramillo, C., MacFadden, B. J., Montes, C., ... Shippritt, M. (2013). Early Miocene chondrichthyans from the Culebra formation, Panama: A window into marine vertebrate faunas before closure the Central American Seaway. Journal of South American Earth Sciences, 42, 159-170. https ://doi.org/10.1016/j.jsames.2012.11.005

Pimiento, C., Griffin, J. N., Clements, C. F., Silvestro, D., Varela, S., Uhen, M. D., \& Jaramillo, C. (2017). The Pliocene marine megafauna extinction and its impact on functional diversity. Nature Ecology \& Evolution, 1, 1100-1106. https://doi.org/10.1038/ s41559-017-0223-6
Rambaut, A. (2009). FigTree v1.4.3. Retrieved from http://tree.bio.ed.ac. uk/software/figtree/

Rambaut, A., Drummond, A. J., Xie, D., Baele, G., \& Suchard, M. A. (2018). Posterior summarisation in Bayesian phylogenetics using Tracer 1.7. Systematic Biology, 67(5), 901-904 https://doi.org/10.1093/sysbio/ syy032

Ree, R. H., \& Smith, S. A. (2008). Maximum likelihood inference of geographic range evolution by dispersal, local extinction, and cladogenesis. Systematic Biology, 57(1), 4-14. https://doi.org/10.1080/10635 150701883881

Riccioni, G., Landi, M., Ferrara, G., Milano, I., Cariani, A., Zane, L., ... Tinti, F. (2010). Spatio temporal population structuring and genetic diversity retention in depleted Atlantic bluefin tuna of the Mediterranean Sea. Proceedings of the National Academy of Sciences of the United States of America, 107(5), 2102-2107. https://doi.org/10.1073/pnas.0908281107

Sperone, E., Parise, G., Leone, A., Milazzo, C., Circosta, V., Santoro, F., ... Tripepi, S. (2012). Spatiotemporal patterns of distribution of large predatory sharks in Calabria (Central Mediterranean, Southern Italy). Acta Adriatica, 53, 13-24.

Steeman, M. E., Hebsgaard, M. B., Fordyce, R. E., Ho, S. Y. W., Rabosky, D. L., Nielsen, R., ... Willerslev, E. (2009). Radiation of extant cetaceans driven by restructuring of the oceans. Systematic Biology, 58(6), 573-585. https://doi.org/10.1093/sysbio/syp060

Stevens, J. D. (2010). Epipelagic oceanic elasmobranchs. In J. C. Carrier, J. A. Musick, \& M. R. Heithaus (Eds.), Sharks and their relatives II: Biodiversity, adaptive physiology, and conservation (pp. 3-37). Boca Raton, FL: CRC Press.

Storai, T., Mojetta, A., Zuffa, M., \& Giulian, S. (2000). Nuove segnalazioni di Carcharodon carcharias (L.) nel Mediterraneo centrale. Atti Società Toscana di Scienze Naturali, 107, 139-142.

Storai, T., Vanni, S., Zuffa, M., \& Biagi, V. (2005). Presenza di Carcharodon carcharias (Linnaeus, 1758) nelle acque toscane (Mar Ligure meridionale e Mar Tirreno settentrionale; Mediterraneo): Analisi e revisione delle segnalazioni (1839-2004). Atti Società Toscana di Scienze Naturali, 112, 153-166.

Suchard, M. A., Lemey, P., Baele, G., Ayres, D. L., Drummond, A. J., \& Rambaut, A. (2018). Bayesian phylogenetic and phylodynamic data integration using BEAST 1.10. Virus Evolution, 4(1), vey016. https:// doi.org/10.1093/ve/vey016

Vandeperre, F., Aires-da-Silva, A., Fontes, J., Santos, M., Serrão Santos, R., \& Afonso, P. (2014). Movements of blue sharks (Prionace glauca) across their life history. PLoS ONE, 9(8), e103538. https://doi. org/10.1371/journal.pone.0103538

Varela, S., González-Hernández, J., Sgarbi, L. F., Marshall, C., Uhen, M. D., Peters, S., \& McClennen, M. (2015). paleobioDB: An R package for downloading, visualizing and processing data from the Paleobiology Database. Ecography, 38(4), 419-425. https://doi.org/10.1111/ ecog.01154

Velez-Juarbe, J., Wood, A. R., De Gracia, C., \& Hendy, A. J. W. (2015). Evolutionary patterns among living and fossil kogiid sperm whales: Evidence from the Neogene of Central America. PLOS ONE, 10(4), e0123909. https://doi.org/10.1371/journal.pone.0123909

Yu, Y., Harris, A. J., Blair, C., \& He, X. J. (2015). RASP (Reconstruct Ancestral State in Phylogenies): A tool for historical biogeography. Molecular Phylogenetics and Evolution, 87, 46-49. https://doi. org/10.1016/j.ympev.2015.03.008

Yu, Y., Harris, A. J., \& He, X. (2010). S-DIVA (Statistical DispersalVicariance Analysis): A tool for inferring biogeographic histories. Molecular Phylogenetics and Evolution, 56(2), 848-850. https://doi. org/10.1016/j.ympev.2010.04.011 


\section{BIOSKETCH}

Agostino Leone is a marine molecular ecologist and population geneticist. Former PhD student at the University of Bologna. He has broad interests in researches related to marine conservation, ranging from biogeography to population genomics, investigating marine populations' structure and their response to different pressures. AL and FT conceived the study; AL, GNP, $E C$ and $A C$ carried out molecular work and sequences analysis; $A L, G N P, F F, P D J$ and GB carried out statistical analyses; ES, ST, PM, AG, MS, MA, GD, FG, ADA, DM, SV and FS collected specimens; AL, GNP, MA, EC, FS, PDJ, GB, AC and FT drafted the manuscript.

\section{SUPPORTING INFORMATION}

Additional supporting information may be found online in the Supporting Information section.

How to cite this article: Leone A, Puncher GN, Ferretti F, et al. Pliocene colonization of the Mediterranean by Great White Shark inferred from fossil records, historical jaws, phylogeographic and divergence time analyses. J Biogeogr. 2020;00:1-11. https://doi.org/10.1111/jbi.13794 